\title{
MAXIMUM POWER POINT TRACKING USING PERTURB \& OBSERVE ALGORITHM FOR HYBRID ENERGY GENERATION
}

\author{
Ghulam E Mustafa Abro' ${ }^{1}$, Gulbadin Khan $\mathrm{Kakar}^{2}$, Rahul Kumar ${ }^{3}$ and Mudasar Zafar ${ }^{4}$
}

\begin{abstract}
No doubt in today's era people are living in the age where there is a huge scarcity in between the production and demand of electrical energy and hence people are deriving electrical energy through renewable energy resources such that photovoltaic plates and high-tech wind turbines. These both have very high impact and potential to meet the above-mentioned scarcity gap. This paper produces a novel approach for prototyping the hybrid energy generation system using solar and wind energy. In addition to this paper proposes the maximum power point tracking (MPPT) using perturb and observe method to increase the efficiency. One may read about the design of this novel hybrid energy system, its hardware implementation with software simulations.
\end{abstract}

Keywords-MPPT, Photovoltaic effect, P\&O Algorithm, and Hybrid Energy System (HES).

\section{Introduction}

In today's era there is a huge scarcity in the production and demand of electrical energy thus, researchers have presented various energy harvesting methods. These energy harvesting methods states that an electrical energy can be produced in different ways such that:

- Solar Energy

- Wind Energy

- Bio-fuels

- Piezo-electric effect etc.

Ghulam E Mustafa Abro ${ }^{1 *}$, Gulbadin Khan $\mathrm{Kakar}^{2}$, Rahul $\mathrm{Kumar}^{3}$ and Mudasar Zafar ${ }^{4,1,3}$ Department of Electrical and Electronic Engineering, Universiti Teknologi PETRONAS, Seri Iskandar, Perak 32610, Malaysia., ${ }^{2}$ Department of Electrical Engineering, Polytechnical University Milano, Italy, ${ }^{4}$ Department of Fundamental and Applied Sciences, Universiti Teknologi PETRONAS, Seri Iskandar, Perak 32610, Malaysia..(email: Mustafa.abro@ieee.org)
This paper focuses at the improvement of efficiency via maximum power point tracking using $P O$ Algorithm. In simple words one may define MPPT as an approach that is used to monitor as well as to extract the point in voltage current (VI) characteristic curve at which the product of current and voltage is comparatively greater than other points as illustrated in the figure 1 . In the mentioned figure 1 , one can see three different power values which are nothing but a product of current and voltages at different instants. Since the intersection point appears due to dotted green lines is the point producing the maximum power value of 224 watts and the work of MPPT is basically to track this point in VI-characteristic curve.

This paper suggests the solar and wind energy-based hybrid generation system (HES). It includes these both sources because of their numerous advantages such that they both are the non-polluting and reliable resources for producing cost effective electrical energy. Commenting on their installation, it is quite easy to deploy and upgrade as per the increment in load requirement. There had been various hybrid energy systems discussed already and this paper provides a comparative analysis of all previously proposed system. Furthermore, everyone has proposed solar with wind energy-based systems. Wind based systems are suggested because of the unlimited free energy producers and its economic value and maintenance cost. As far as deploying wind power in Pakistan is concerned almost $6 \%$ of the total electricity has been contributed by wind powerbased stations. As per the statistics of the year 2020 the wind power capacity of Pakistan is almost 1235 MW. Simply hybrid energy systems are becoming very popular because of their quality of increasing efficiency as well as providing the energy as per the requirement of load. 
Researchers are preferring solar energy because it is renewable and environment friendly in nature. Now researcher found the efficiency of solar is approximately to $25 \%$. Whereas the efficiency of solar panel is one of the important factors now a days. Improving the efficiency of solar is one of the research topics. Discussing the perks of solar panel, these panels are also non-polluting with no hazardous rays, efficient in terms of reliability, no fossil fuel needed, fuel-abundant and all time available. These panels can be further used as a distributed generation. In addition to this, installation is also easy and can be upgraded easily as per the requirement of the load.

\subsection{About Solar-based Cells}

Discussing solar based cells, they are the essential tools of photovoltaic sheets. These cells are majorly adjusted by the commencement of silicon and other unique resources. Solar based cells create a preferred stand-point of the photoelectric outcomes such that the limit for the couple of semiconductors to change the electromagnetic emission which is directly addicted to electrical current. The thrilling speck made via the experience emission are removed suitably to make an electrical current by a genuine diagram of the configuration of the sun-based cell, like spirit be cleared up underneath. A sun situated cell is on an extremely fundamental level because of a p-n crossing point which is set up from two oneof-a-kind layers of atomic number 14 doped with a bit measure of corruption particles. Because of the n-layer, particles with one more negatron, called benefactors, and by virtue of the p-layer, with one less negatron, called acceptors. Exactly once the two mantles are concatenate; close to edge the free electrons of the n-mantle are subtle in the p-side, forsaking a district determinedly stimulating by the suppliers. This makes an association of a pasture of force amid the two side explicitly a budding block headed for furthermore rivulet. The concordance is draw closer to the convergence once the electrons and hole cannot outflank that prospective hindrance. This pasture of force pulls the electrons and openings in contrary ways that the current will rivulet in single mode. The outline of the $p-n$ juncture demonstrating the brunt of the specified field of force whose brief illustration can be seen in figure 2. This means, one can model a single solar cell by replacing it with an equivalent circuit. This equivalent circuit may consist of a current source with a diode and parallel resistance $R_{s h}$ and a series resistance through the load illustrated as $R_{\text {ser }}$ as shown in figure 3 . This mathematical model is further used to design a Simulink model for further analysis and to notice the change in PV and VI curve.

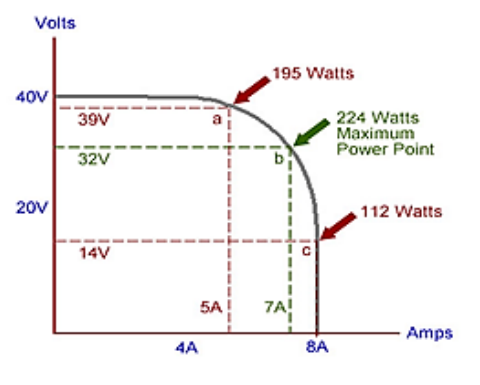

Figure 2: Maximum power point tracking (MPPT)
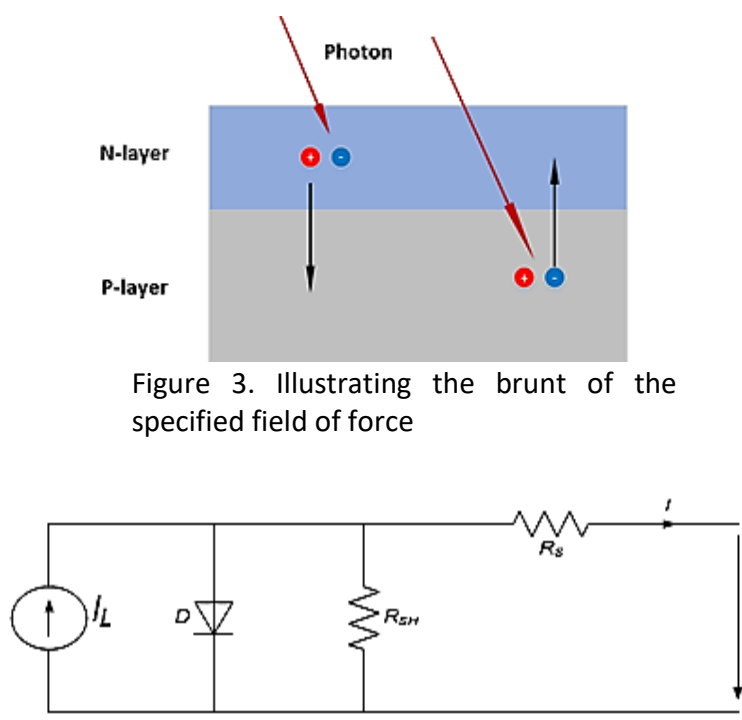

Figure 1Figure 3. Equivalent circuit for the solar cell.

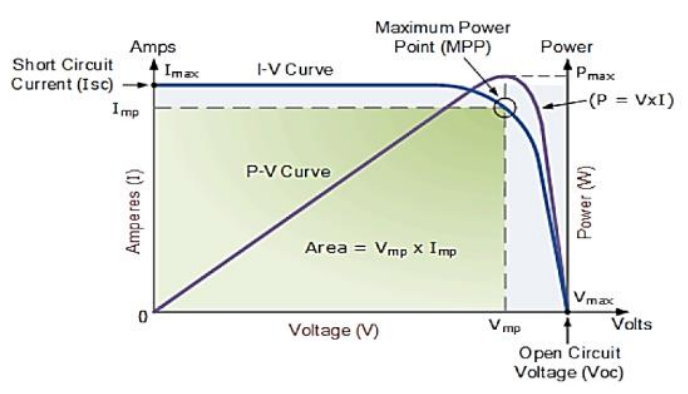

Figure 4. Illustrating the MPPT graph using PO Algorithm

II. Literature Review

One may see the fusion of PV with other hybrid systems to provide the best promising solution ever seen in this field. It does not only improve the overall system but also improvise the system power 
conversion efficiency in percentage [1-4]. Researchers have proposed such practical implementations that are usually fabricated in a sophisticated manner with various thermoelectric elements commonly known as (TEs). Moreover, the examples for TEs can be thermocouples that are operated based on a specific effect [5] [6]. These approaches have already improved the adequacy of output voltages and have special structure to make sure for better thermal conductance by maintaining low temperature that is known as cold side and hot side structure. Due to these structures, it can convert a wasted heat energy into a noticeable required form of energy i.e. electrical voltage and current [7-9]. It has been observed that this trend of fusion has been stopped for a long time due to the low-efficiency factor [10].

Recently, one may find several articles and

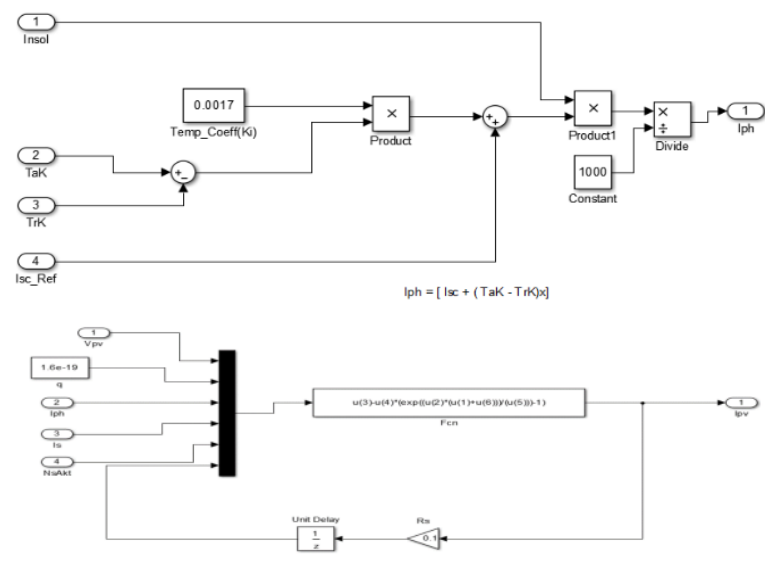

Figure 5. Simulink Subsystem for Photo current equation

manuscripts where the conversion of wasted heat is turned into PV array due to incident solar irradiation [12]. Researchers have assessed various ways to commercialise these techniques [3] and for this regard, many experiments have been conducted too as illustrated in [13] where such technique is used in PV amalgamated system HES for water pumping and other [14] applications. The MPPT technique is not a new one technique as researchers have proposed it in different versions as described in [15]. Researchers have also mentioned some of the pros and cons for different applications as mentioned in [16]. For MPPT, the most frequent techniques are incremental method [16], climbing hill technique (CHT) as shown in [17], PO strategy or algorithm in [18-19], artificial neural network based algorithms [20], fuzzy logic based control algorithm [21]. Fractional open-circuit method (FOCM) [22]. LE-MPPT technique [23] that stands for linear extrapolation-based MPPT strategy and lastly VT-
MPPT method [24] that stands for variation-tolerant MPPT technique.

\section{Modeling Equations}

In this section, author is discussing the main equations that are modelled in Simulink such that saturation current. Saturation Current is the part of reverse current in PV module that is equivalent to a simple circuit with a diode. This saturation current equation is mentioned as:

$$
\begin{aligned}
& I_{r s} \\
& \exp \left(\frac{q * V_{o c}}{n * N_{s * K * T}}\right)-1
\end{aligned}
$$

In Simulink it has been implemented as shown in figure 4:

whereas the photo current equation is given as:

$$
I_{p h}=\left[I_{s c}+\left(T_{a K}-T_{r K}\right) x\right]
$$

This equation can be designed in Simulink as given in figure 5:

Similarly, the module output current can be given as in equation (3) and subsystem design in figure 6:

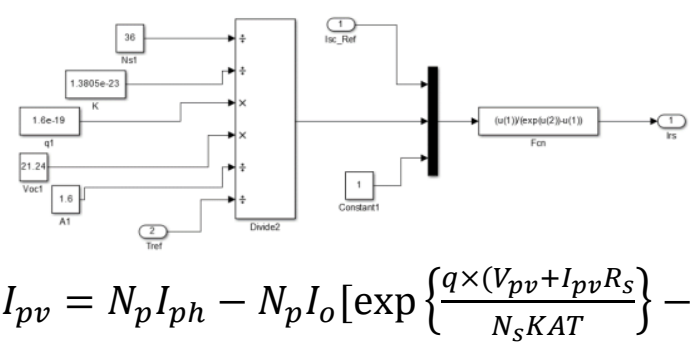

1]

MPPT using PO Algorithm is used to analyse the tracking phenomenon using scope and the responses are plotted in Simulink. In PO algorithm, initial current and voltage is measured using current sensor and voltage sensor and then product of these to give us power. Whereas, in next perturbation previous power is compared with the current power rating and according to the power values duty cycle of the DCDC converter varies and follows the algorithm. This entire flow of the process is highlighted in the flow chart shown in figure 7. 


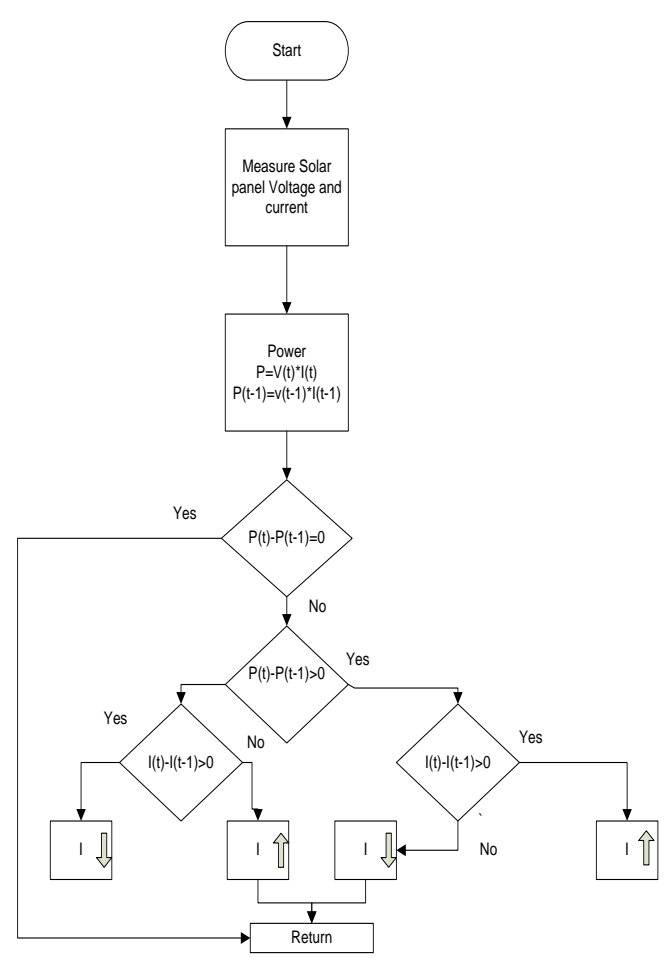

Figure 7: Flow chart for the MPPT using PO Algorithm

IV. Results

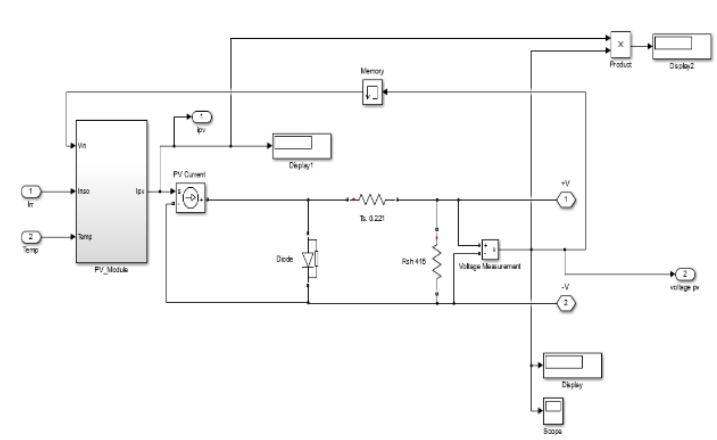

After studying this entire procedure, one may design the subsystems and PV module as shown in figure 8 and 9 respectively.

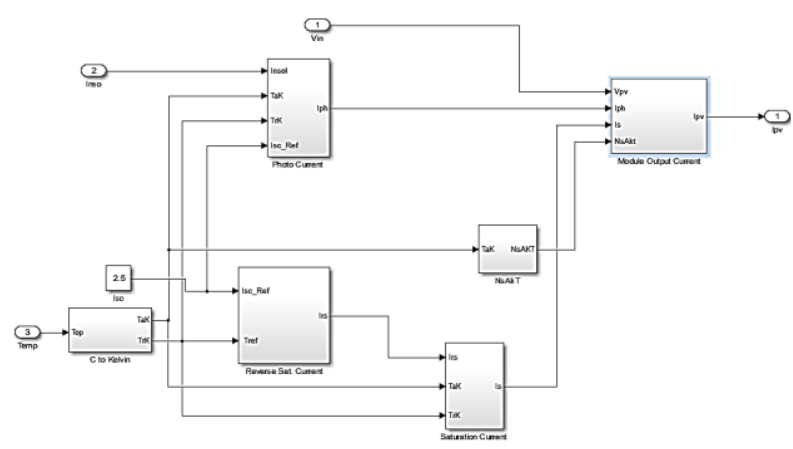

Figure 8: Complete subsystem

Whereas the complete PV module can design as shown in the illustration below:

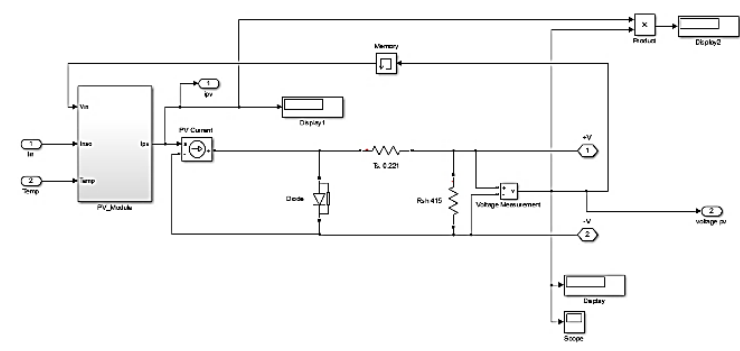

Figure 9: Complete PV Module implementation using Simulink

Whereas the wind module can be illustrated as:

Figure 10: Complete PV Module with entire system implementation using Simulink

Moreover, the block of PV System comprises of below topology as shown in figure 11:

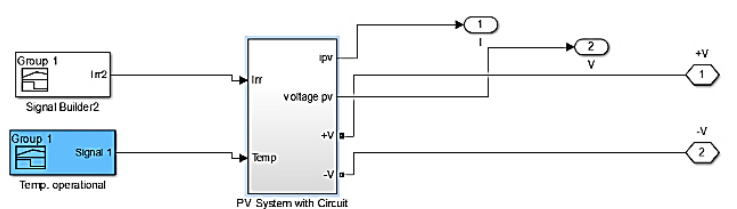

Figure 11: The Block of PV System

Since, wind source had two of things essential such that radius $r$ and the sweep area as shown in figure 12.

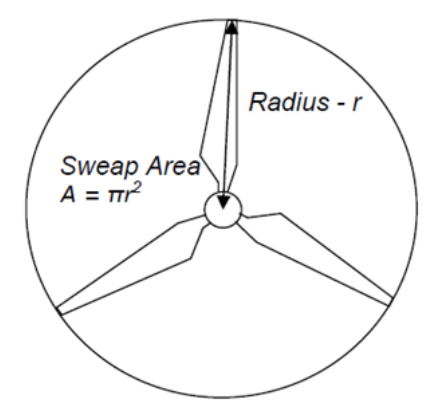

Figure 12: Wind as renewable resource

The equations for the wind renewable resource are as mentioned below:

$P=\frac{1}{2} \rho A v^{3}$ 
$A=\pi r^{2}$

(4)

$$
P_{\text {avail }}=\frac{1}{2} \rho A v^{3} C_{p}
$$

After seeing these equations are now turned into Simulink module as:

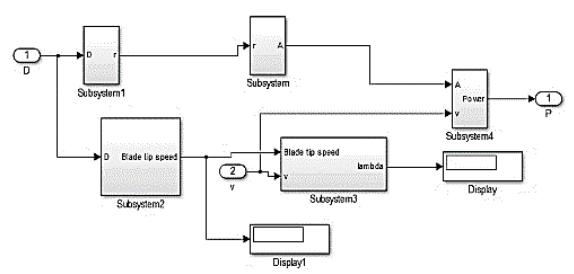

Figure 13: Wind as renewable resource

Therefore, the entire Simulink mode can be designed as shown below in figure 13 .

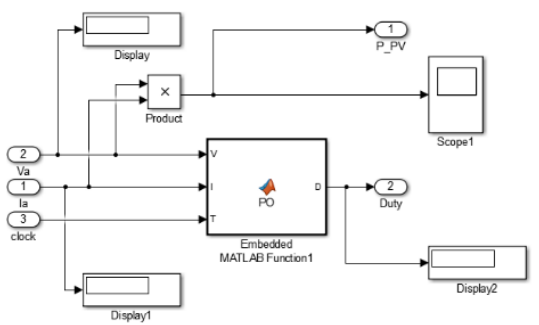

Figure 13: Complete HES Design Using MATLAB and Simulink.

In this research manuscript, there was a need of one buck converter that can convert and regulates the direct current and voltage accordingly. The buck converter topology is designed and shown in figure 14:

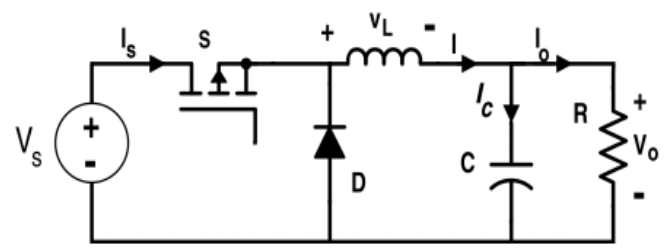

Figure 14: Simple topology for Buck Converter

In our simulation, the PV source is connected to apply input to Buck converter and later, the control signal will enable the MOSFET switch to acquire the needed duty cycle for regulating. MPPT here with

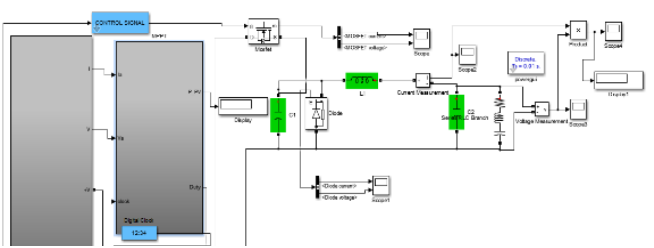

Figure 15: Entire Algorithm in Simulink
PO Algorithm control this switching. The frequency of buck converter is set to $20 \mathrm{Khz}$. One may see the brief calculations as mentioned below:

$V_{\text {out }}=V_{\text {in }} * D$, whereas $D=\frac{V_{\text {out }}}{V_{\text {in }}}=\frac{10}{21}$

$=0.6 * 100$

$=60 \%$ duty cycle

The load resistor here is opted in between the range of 10-12 ohms thus, the value for inductance and capacitance can be calculated as:

$L=\frac{(1-D) R}{2 f}=1.25 * 10-4$

$=0.156 \mathrm{mH}$

Similarly, for the calculation of number of turns:

Let's say $r$ is radius and $l$ is the length and $L$ is inductor value thus, voltage ripple can be calculated as:

$\Delta i_{L}=\frac{V_{o}(1-D)}{L f}=\frac{10(1-0.5)}{(6.25 e-5)(20 e 3)}$

$=4$

Whereas $\Delta i_{L}=$ inductor ripple current, $C=$ capacitor. Since, ripple voltages must be very small therefore we will consider the value as 0.1 and compute the value for capacitance as shown below:

$C=\frac{T \Delta i_{L}}{8 V_{o}}=\frac{1 / 20000(4)}{(8)(0.1)}=0.00025$

$=250 \mu \mathrm{F}$ 


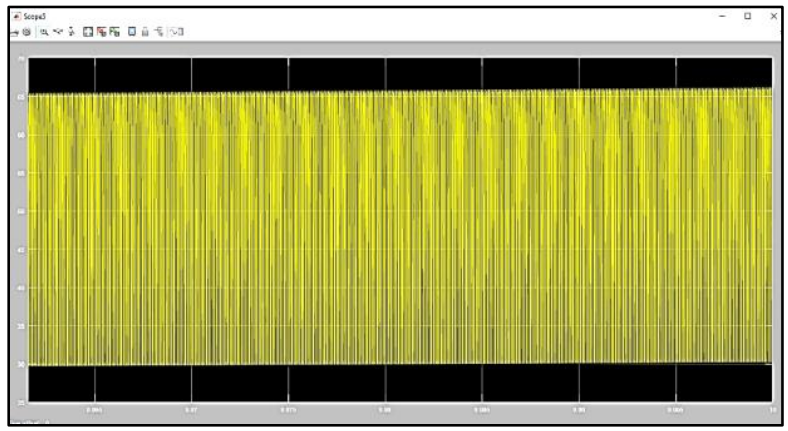

Figure 16: Tracking Performance

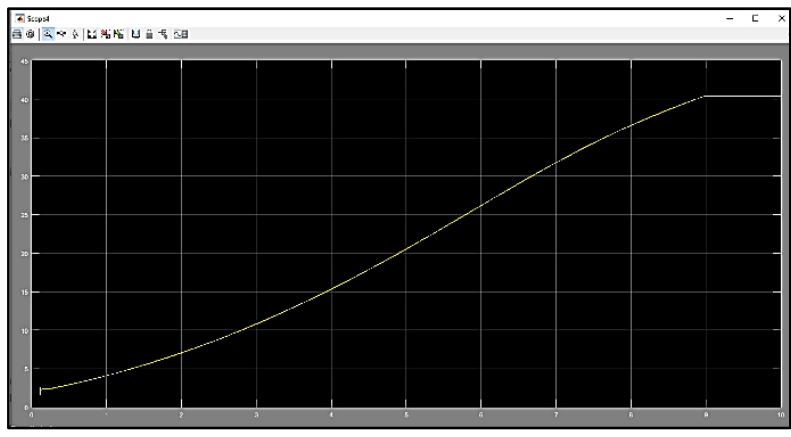

Figure 17: Output shown in scope

In this simulation, when one will find that solar module generates 40 Watt and Wind turbine produces 30 watts out of 50 watt due to losses of wind turbine and 36 watt of PV module track by MPPT Algorithm which is because of PO Algorithm. Figure 15 show complete system with output of PV and total output. During sunlight this complete system operate to generate $65 \mathrm{~W}$ whereas in the absence of sunlight when there is no irradiance for PV module, the output power approaches to zero watt and here then wind turbine generates power and our total power will not drop and later one may also charge the Batteries as well.

\section{Conclusion}

This paper provides the hybrid system regulated for the maximum power point tracking using PO algorithm. One may find the state-of-the-art approaches being discussed here in this manuscript. Later, the essential calculation for buck converter is also witnessed along with proposed MOSFET switch design. This approach can stimulate and provide the better power ratings in the sunlight and even in the sunlight, this hybrid system provides the same power ratings with an additional perk for charging the batteries.

\section{Acknowledgement}

This work is being carried with the join research collaboration with the department of electrical engineering, Polytechnical University Milano, Italy. Thus, all authors wish to acknowledge this support.

\section{Conflict of Interest}

There is no conflict of interest among the authors Sponsorship

This work is not sponsored by any of the funding or Grants.

\section{REFERENCES}

[1]. Babu, C.; Ponnambalam, P. The theoretical performance evaluation of hybrid PV-TEG system. Energy Convers. Manag. 2018, 173, 450-460. [CrossRef]

[2]. Attivissimo, F.; Di Nisio, A.; Lanzolla, A.M.L.; Paul, M. Feasibility of a photovoltaic thermoelectric generator: Performance analysis and simulation results. IEEE Trans. Instrum. Meas. 2015, 64, 11581169. [CrossRef]

[3]. Hasanuzzaman, M.; Malek, A.B.M.A.; Islam, M.M.; Pandey, A.K.; Rahim, N.A. Global advancement of cooling technologies for PV systems: A review. Sol. Energy 2016, 137, 25-45. [CrossRef]

[4]. Ahmet, S.; Kehinde, I.; Bekir, Y.; Abdullah, S. A review on the performance of photovoltaic/thermoelectric hybrid generators. Int. J. Energy Res. 2020, 44, 3365-3394.

[5]. Meng, J.H.; Zhang, X.X.; Wang, X.D. Characteristics analysis and parametric study of a thermoelectric generator by considering variable material properties and heat losses. Int. J. Heat Mass Transf. 2015, 80, 227-235. [CrossRef]

[6]. Laird, I.; Lu, D. High step-up DC/DC topology and MPPT algorithm for use with a thermoelectric generator. IEEE Trans. Power Electron. 2013, 28, 3147-3157. [CrossRef]

[7]. Hsiao, Y.Y.; Chang, W.C.; Chen, S.L. A Mathematic Model of Thermoelectric Module with Applications on Waste Heat Recovery from Automobile Engine. Energy 2010, 35, 1447-1454. [CrossRef]

[8]. McEnaney, K.; Kraemer, D.; Ren, Z.; Chen, G. Modeling of Concentrating Solar Thermoelectric Generators. J. Appl. Phys. 2011, 110, 074502. [CrossRef]

[9]. Kumar, S.; Heister, S.D.; Xu, X.; Salvador, J.R.; Meisenr, G.P. Thermoelectric generators for automotive waste heat recovery systems. Part I: Numerical modeling and baseline model analysis. J. Electron. Mater. 2013, 42, 665-674. [CrossRef]

[10]. Wang, P.; Wang, B.L.; Li, J.E. Temperature and performance modeling of thermoelectric generators. Int. J. Heat Mass Transf. 2019, 143, 1145-1153. [CrossRef]

[11]. Kanagaraj, N.; Rezk, H.; Gomaa Behiri, M.R. A variable fractional order fuzzy logic control based MPPT technique for improving energy conversion efficiency of thermoelectric power generator. Energies 2020, 13, 4531. [CrossRef]

[12]. Lin, J.; Liao, T.; Lin, B. Performance analysis and load matching of a photovoltaic-thermoelectric hybrid system. Energy Convers. Manag. 2015, 105, 891-899. [CrossRef]

[13]. Ibrahim, N.M.; Rezk, H.; Dahifallah, M.A.; Sergeant, P. Hybrid photovoltaic-thermoelectric generator powered synchronous reluctance motor for pumping 
applications. IEEE Access 2019, 7, 146979-146988. [CrossRef]

[14]. Mohd Shatar, N.; Abdul Rahman, M.A.; Muhtazaruddin, M.N.; Shaikh Salim, S.A.Z.; Singh, B.; Muhammad-Sukki, F.; Bani, N.A.; Saudi, A.S.M.; Ardila-Rey, J.A. Performance evaluation of unconcentrated photovoltaic-thermoelectric generator hybrid system under tropical climate. Sustainability 2019, 11, 6192. [CrossRef]

[15]. Verma, V.; Kane, A.; Singh, B. Complementary performance enhancement of PV energy system through thermoelectric generation. Renew. Sustain. Energy Rev. 2016, 58, 1017-1026. [CrossRef]

[16]. Lin, C.H.; Huang, C.H.; Du, Y.C.; Chen, J.L. Maximum photovoltaic power tracking for the PV array using the fractional-order incremental conductance method. Appl. Energy 2011, 88, 48404847. [CrossRef]

[17]. Nzoundja, F.C.B.; Patrice, W.; Martin, K.; Abderrezak, B.; Hyacinthe, T. Real-time experimental assessment of hill climbing algorithm enhanced by estimating a duty cycle for PV system. Int. J. Renew. Energy Res. 2019, 9, 1180-1189.

[18]. Fuqiang, C.; Yu, G.; Xiaohong, G.; Xian, Y.; Liangwei, F.; Lin, S.; Xing, H.; Kun, Z.Z.; Chao, W.; Weitao, Z. Fabrication of nanostructured skutteruditebased thermoelectric module and design of a maximum power point tracking system for the thermoelectric pile. IEEE Sens. J. 2019, 19, 58855894.

[19]. Subudhi, B.; Pradhan, R. A comparative study on maximum power point tracking techniques for photovoltaic power systems. IEEE Trans. Sustain. Energy 2013, 4, 89-98. [CrossRef]

[20]. Serhat, D.; Nuran, Y.; Ismail, A. A novel MPPT algorithm based on optimized artificial neural network by using FPSOGSA for standalone photovoltaic energy systems. Neural Comput. Appl. 2018, 29, 257278.

[21]. Junaid, K.M.; Lini, M. Fuzzy logic controller-based MPPT for hybrid photo-voltaic/wind/fuel cell power system. Neural Comput. Appl. 2019, 31, 6331-6344

[22]. Montecucco, A.; Knox, A.R. Maximum power point tracking converter based on the open-circuit voltage method for thermoelectric generators. IEEE Trans. Power Electron. 2015, 30, 828-839. [CrossRef]

[23]. Bijukumar, A.; Raam, A.G.K.; Ganesan, S.I.; Nagamani, C. A linear extrapolation-based MPPT algorithm for thermoelectric generators under dynamically varying temperature conditions. IEEE Trans. Energy Convers. 2018, 33, 1641-1649. [CrossRef]

[24]. Kim, J.; Kim, C. A DC-DC boost converter with variation-tolerant MPPT technique and efficient ZCS circuit for thermoelectric energy harvesting applications. IEEE Trans. Power Electron. 2012, 28, 3827-3833. [CrossRef] 